\title{
RESENHAS
}

DONHAM, Donald L. 2011. Violence in a time of liberation. Murder and ethnicity at a South African gold mine. Durham and London: Duke University Press. 238 pp.

\section{Daniel Belik}

Mestre em Antropologia Social pela University of Aberdeen

Na mina de ouro chamada de Cinderela por Donald Donham, dois trabalhadores zulus são linchados até a morte em 1994. O episódio, que anteriormente teria passado despercebido, recebeu bombardeio imediato da mídia local, que pautou o acontecimento como fruto das infindáveis lutas étnicas, protagonizadas pelas gangues locais. À época, a tentação de equacionar um ato moral com um desfecho étnico era não só sedutora, como plausível, tendo em vista a segregação na cidade e no país aplicada ao mundo do trabalho nas minas.

O autor, no entanto, não aceita leituras simplistas, procurando enxergar o assassinato como sintoma de um país que cozinha em fogo brando e que entra em ebulição quando findo o apartheid, ou seja, quando alcançada a possibilidade de reconfiguração da identidade negra após uma longa e violenta luta para a libertação nacional.

A princípio, o objetivo de Donham era estudar as mudanças que o fim do regime gerou na organização da produção na África do Sul. Os assassinatos, no entanto, modificaram radicalmente seu trabalho de campo e, a partir desse momento, ele passou a investir mais nas relações micropolíticas vigentes na extração de ouro e em sua ligação com este Estado em transformação. Com um texto respeitoso, o autor tenta quebrar o efeito monolítico do apartheid, fazendo aparecer a conformação mútua de brancos e negros na nova realidade. O livro abre com a descrição da estrutura geral da mina de Cinderela e da dinâmica cotidiana de seus atores, dando especial ênfase à composição multiétnica de seus trabalhadores. No capítulo seguinte, transcreve extensamente os registros de atas na mina, feitos por brancos, no momento do ocorrido, para no terceiro e quarto capítulos problematizar "internamente" a questão, aproximando-se mais da cosmovisão negra daquele trabalho e de suas estratégias de sobrevivência em um ambiente quase nunca favorável e etnicamente demarcado.

Estes dois pontos de vista iniciais abrem espaço para que no quinto e sexto capítulos o autor discuta o paternalismo branco existente na África do Sul em relação aos trabalhadores negros e como, por sua vez, esta mentalidade influenciou a configuração histórica das uniões sindicais, por vezes retardando a modernização das relações trabalhistas nas minas 
deste país. O livro termina retornando ao episódio que foi o estopim de seu trabalho de campo, para agora discutir de maneira bem mais nuançada as possíveis causas da morte dos trabalhadores zulu em face da mudança de status dessas pessoas diante da liberalização.

Episódios de violência coletiva trapaceiam a memória pela intensidade e pelo trauma, tornando fácil tanto a manipulação dos interessados na situação como a simplificação de suas causas, a ponto de entendermos o ocorrido pelo seu final, enfiando os pés pelas mãos. Neste sentido, $\mathrm{o}$ esforço do autor será de deslocar as explicações que reduzem o linchamento a um mero conflito étnico, demonstrando que direitos (ou a falta deles) e a emergência dos primordialismos étnicos se deram pari passu, e que apontar para apenas um destes aspectos como causa para os assassinatos é perigosamente parcial. Para isso, procura driblar explicações incriminadoras, especialmente aquelas que, pelo choque causado pela violência, em um primeiro momento se restringem a estigmatizar os envolvidos.

A busca por uma narrativa alternativa não é feita somente por Donham. Ao longo do livro, o fotógrafo sul-africano Santu Mofokeng nos fornece um valioso registro imagético das cenas descritas pelo antropólogo, guarnecendo o leitor de uma figura mais próxima e detalhada do cenário de Cinderela e seus arredores. Suas fotos trazem as fisionomias dos trabalhadores das minas e os panoramas do cotidiano do lugar. Tudo nos remete ao clima do assassinato. Parece que sua intenção é fazer com que o leitor se "engaje" e descubra quem são os verdadeiros culpados pelo crime. Porém, por mais certeza que tenhamos, nunca haveremos de achar um único responsável. Dentro desta arqueologia da memória, feita de continuidades e disjunções, a principal distinção a ser feita é entre a história nacionalista negra e a história étnica. No decorrer do livro, e como que disparadas pelo episódio citado, as duas narrativas de que nos damos conta se imiscuem, tendo em vista a eminente redemocratização do país e a organização multiétnica dos trabalhadores.

Com o preço do ouro fixado no mercado internacional, a única forma de lucrar era produzindo-o mais barato. E isto foi facilmente atingido, não tanto pelo investimento em novas tecnologias, mas inundando as minas de mão de obra negra mal remunerada e impedida por lei de se qualificar e suplantar o patamar salarial dos brancos. De um lado, portanto, a pobreza dos negros e a ausência de seus direitos trabalhistas se relacionam com a tardia sindicalização nas minas. Somente no início dos anos 80 chega-se à legalização dos sindicatos mineiros negros e à formação da NUM (União Nacional dos Trabalhadores Mineiros), vinculada ao partido de Mandela, o ANC (Congresso Nacional Africano), comprometido com a liberação negra. Entretanto, dada a bancarrota generalizada, a margem de atuação dos sindicatos que emergiam não se mostrava muito ampla. Embora a legalização da cidadania negra tenha melhorado em parte a vida de mais da metade da população, um pequeno segmento negro encontrou meios para acumular poder econômico. Ao fugir da história mais corrente, já muito bem documentada sobre o sindicalismo branco na África do Sul, o autor é capaz de mostrar o outro lado da moeda colonial: os ambíguos acordos políticos entre capital e trabalho no pós-apartheid.

Esta situação de paternalismo e injustiça não era uma novidade. Conflitos étnicos de ordem similar marcaram a década de 70. A construção da identidade dos "grupos étnicos" nas minas, que envolvia uma intolerância étnico-cultural, inclusive entre negros, ecoava ares de 
família com a proposta do governo nacionalista de independência dos bantustões. A diversidade formada por zulus, xhosas, sothos e mesmo moçambicanos (Changana) que chegavam para trabalhar em Cinderela era reificada e reforçada pelos gerentes das minas, que segregavam as diversas "etnias". Esses trabalhadores permaneciam sob a tutela do seu empregador branco, uma forma de paternalismo igualmente sempre presente nas fazendas. Os patrões se justificavam afirmando que os negros eram supersticiosos e infantis, devendo ser ensinados em como adentrar o mundo capitalista.

Orquestrado pelo poder mundial, o preço do ouro passou a cair, coincidindo com as incertezas políticas pela libertação de Mandela no início dos anos 90 e o temor acerca da proteção da propriedade privada. A África do Sul vivia os rumores de uma transição política e a euforia do fim da segregação racial, o que forçou o fechamento de muitas minas. Na primeira década do pós-apartheid, a mina de Cinderela mudou de mãos várias vezes - sendo por fim adquirida por um sul-africano negro. As promessas de uma "Nova África do Sul" e a de encontrar ouro na mina de Cinderela caíam por terra.

O estilo de escrita do livro também apresenta elementos pouco usuais para a temática. Na tentativa de fazer a microhistória de uma mina de ouro refletir fenômenos políticos de ordem continental, Donham transcreve registros do livro de atas da mina, bem como parte integral dos depoimentos dos suspeitos no momento do julgamento. Os diálogos e as fotografias tornam, neste sentido, o livro pouco árido e de agradável leitura, mesmo para um leigo no assunto.

Por fim, apesar de uma excelente visão contextual das mudanças políticas, enfrentamentos étnicos e burocratização das relações econômicas nas minas da África do Sul no período de transição do apartheid, o livro pouco explora as influências cosmológicas que podem ter permeado o ato do assassinato. Sabe-se pouco sobre a rotina desses trabalhadores nas entranhas da terra e sobre como a especialização nas tarefas garimpeiras influía na maneira com que cada grupo étnico definia sua condição. Neste sentido, cita-se que os Swazis por um lado, formavam um importante grupo de perfuradores do solo, e por outro, que eles também acreditavam no poder curativo do "muti", sua medicina tradicional capaz de aumentar o rendimento da tecnologia usada na extração do ouro. Ainda assim, as consequências do uso e da venda do "muti" dentro desta economia de divisão étnica do trabalho são pouco aprofundadas.

Além disso, pelo forte viés marxista que o autor imprime à narrativa, o livro sofre a inevitável tendência de essencializar dados culturais, como a riqueza dos relatos dos trabalhadores e as inúmeras ramificações e pistas que os mesmos poderiam nos trazer acerca das cosmologias nativas. Fica pouco claro para o leitor, por exemplo, a razão pela qual, nos dias de hoje, os donos das minas mudaram de estatuto ontológico aos olhos de seus trabalhadores. Os brancos são agora vistos menos como mediadores sacrificiais entre a evitação da morte para extração do ouro e mais como vampiros ou bruxas que, através do sangue, traficam dinheiro. Seria esta uma consequência direta das mudanças ocorridas em nível nacional? Quais as possíveis transformações pelas quais passa a ideia de sangue à luz das novas concepções econômicas? Permanece obscura no livro a relação existente entre sangue e dinheiro no entendimento dos trabalhadores negros sobre as minas. Com a possibilidade de dialogar com a literatura etnográfica acerca do canibalismo das minas, que sustenta seu funcionamento baseado no consumo de trabalhadores humanos, a análise do 
autor restringe-se a transcrever um breve trecho desta mitopoética que descreve as negociações que deveriam ser feitas entre os donos das minas e a cobra guardiã-metade humano, metade animal para que o ouro pudesse ser extraído sem nenhum contratempo.

Apesar destas questões abandonadas pelo caminho, à medida que o leitor transita por este belo livro, Donham nos deixa, ao menos, com a sugestão analítica de que, de longe, a Nova África do Sul estava unida após a eleição de Mandela, mas que, de perto, em seu cotidiano, encontrava-se fraturada pelas feridas anteriores, legadas pelo colonialismo e pelo apartheid.

LIGIÉRO, Zeca (org.). 2012. Performance e antropologia de Richard Schechner. Rio de Janeiro: Mauad X. 199 pp.

\section{Luciane Moreau Coccaro}

Doutoranda do PPGSA do IFCS/UFRJ.

A coletânea de quatro ensaios de Richard Schechner sobre performance e antropologia, organizada por Zeca Ligiéro, é uma iniciativa necessária devido ao ineditismo destes textos em português. Esta tradução resulta relevante porque, apesar de a área ter uma longa tradição internacional nos debates em ciências sociais, os Estudos da Performance têm uma difusão limitada na antropologia no Brasil, especialmente na Pós-Graduação: apenas quatro instituições federais têm oferecido em seus currículos esta disciplina. Por um lado, o livro cumpre seu papel na divulgação das principais reflexões sobre performance feitas pelo diretor teatral e antropólogo Schechner, um dos principais protagonistas deste campo de pesquisa, que tem origem no diálogo entre a Antropologia e o Teatro Experimental, fruto de seu encontro com Victor Turner. Por outro lado, o livro inclui uma entrevista com Schechner, na qual ele oferece um mapeamento das condições sociais e artísticas da época do surgimento dos Estudos da Performance em Nova York, no ano de 1966.

A área da Performance no Brasil começa a ser difundida nas universidades no final dos anos 80, e dela fazem parte alguns trabalhos pioneiros, mas como campo de estudo ainda não alcançou grande destaque. Ligiéro afirma que os Estudos da Performance, no país, estão hoje sendo disseminados em quase todos os cursos de Pós-Graduação em Teatro e em Antropologia (:15). Com base nesta afirmação, fui pesquisar em quantas e em quais Pós-Graduações podemos encontrar uma disciplina ou linha de pesquisa ligada à Performance. No entanto, após analisar a oferta de disciplinas nos últimos 20 anos, das 13 Universidades Federais que oferecem Programas de PósGraduação em Antropologia no Brasil, apenas quatro têm em seu currículo, com alguma regularidade, esta disciplina: UFRGS, USP, UNB, UFSC. Na graduação em Ciências Sociais, dificilmente o tema da Performance está presente, pois a bibliografia, até a publicação do livro de Ligiéro, era majoritariamente em inglês, o que poderia representar um obstáculo para a difusão do campo de Estudos da Performance no Brasil.

A publicação deste livro, com a tradução dos textos de Schechner, evidencia uma demanda das áreas com as quais a Teoria da Performance tem dialogado: o teatro, a dança e, fundamentalmente, a antropologia. Schechner faz parte da vertente dramatúrgica dos Estudos da Performance, inaugurada por Erving Goffman e Victor Turner, que considera a performance um comportamento humano, no qual conflitos sociais podem 
ser comparados com o drama. Não por acaso, o livro é uma ideia de Ligiéro, que é professor do curso de Artes Cênicas da Unirio, coordenador do Núcleo de Pesquisa em Performance Afro-Ameríndia (NEPAA) e um dos responsáveis por trazer Schechner mais de uma vez ao Brasil para ministrar oficinas ou palestras, e também para o lançamento deste livro.

Para além da divulgação e da consolidação da área dos Estudos da Performance no Brasil, o livro é necessário e bem-vindo aos debates específicos em antropologia. A Teoria da Performance lida diretamente com temas-chave tanto da teoria antropológica clássica quanto da teoria antropológica contemporânea - ritual, corpo, emoções e arte - a partir de uma perspectiva totalizadora. Na breve introdução, "O leque e a rede", retirada do prefácio do livro Performance theory (1988), Schechner afirma que o termo performance é inclusivo. Numa das definições do autor a performance: " [...] vai desde ritualizações [...] às performances na vida cotidiana celebrações, demonstrações de emoções, cenas familiares, papéis profissionais [...] jogos, esportes, teatro, dança, cerimônias, ritos - e às apresentações espetaculares" (:18): uma noção de performance ampliada que permite o diálogo com as mais diversas práticas culturais, ultrapassando as manifestações artísticas.

O livro está dividido em quatro partes: Prefácio, Introdução, Entrevista, Ensaios de Richard Schechner. No Prefácio, Ligiéro descreve sua experiência como orientando de Schechner na NYU (Universidade de Nova York), no Departamento de Estudos da Performance, detalhando o quanto o currículo do curso é interdisciplinar e intercultural, uma vez que abrange tanto estudos da arte, como dança e teatro, quanto outras áreas das ciências sociais e da teoria crítica.

Na terceira parte, após a Introdução já mencionada, há uma entrevista com
Schechner, na qual ele narra o movimento artístico dos anos 60, em Nova York, como um período de forte imigração para a cidade de diversos artistas e pensadores europeus. Algumas explicações sobre o nascimento dos Estudos da Performance estão relacionadas a esses encontros interculturais. Schechner conta como conheceu Victor Turner e que, antes mesmo de conhecer o antropólogo, já compartilhava algumas de suas ideias sobre drama social, liminaridade, ritual e communitas (:38-39). Estas informações históricas sobre o contexto do surgimento desta área de saber, bem como da aproximação de Schechner com Turner, reforçam a importância do campo de Estudos da Performance como uma ponte verdadeiramente interdisciplinar e heuristicamente produtiva para as artes e para a antropologia.

No último capítulo encontramos quatro ensaios de Schechner: "Ritual" e "Jogo" ambos retirados de Performance studies: an introduction (2002); "A estética do Rasa", do livro The drama review (1988); e "A rua é o palco", da obra The future of the ritual (1995). Nos dois primeiros, Schechner aponta possibilidades de definição do termo performance como fruto da interação entre ritual e jogo: “[...] a performance pode ser um comportamento ritualizado condicionado/permeado pelo jogo" (:49, 91). O autor leva em consideração aspectos fluidos das performances capazes de serem caracterizados como ritual ou como jogo ou, ainda, conterem aspectos de ambos. A ritualização e a diversão podem estar presentes num mesmo evento performatizado, como ação eficaz e entretenimento.

O autor inicia o ensaio "A estética do Rasa" perguntando: "Onde está localizada a teatralidade do corpo?". O tópico aborda o sistema nervoso entérico ou cérebro do sistema gastrointestinal, que seria nosso segundo cérebro e o local 
das emoções e das intuições. Esta ideia encontra reverberação no Rasa, sensação de prazer descrita pelos indianos numa refeição, mas também ao se assistir a um espetáculo, uma emoção física. O texto se desenrola em direção à descrição de uma prática desenvolvida pelo autor: o exercício Rasabox, que parte do princípio de que as emoções podem ser treinadas fisicamente. O tema tem ocupado a reflexão de outros autores, como Ingold (2010).

No último ensaio, "A rua é o palco", Schechner descreve e analisa seis eventos performáticos de ocupação de espaços públicos emblemáticos, documentados pela mídia, e que têm significados e desfechos distintos. Schechner, assim como Turner, vê a relação entre ritual e teatro como dialética e interligada. O seu conceito de restauração de comportamento é fundamental para o entendimento de que no cotidiano, sobretudo na presença dos outros, estaríamos sempre performatizando e/ou ritualizando a partir de experiências e situações já vividas por nós mesmos. Este ensaio pode ser interessante para antropólogos estudiosos da antropologia urbana, em especial para pesquisas sobre movimentos sociais, incluindo diferentes manifestações sociais públicas, como protestos de rua, passeatas, greves, entre outras possibilidades de utilização dos espaços públicos.

PALMIÉ, Stephan \& SCARANO, Francisco (eds.). 2011. The Caribbean. A history of the region and its people. Chicago: University of Chicago Press. 660 pp.

\section{Marcelo Moura Mello}

Doutorando PPGAS/Museu Nacional/UFRJ

O título e o subtítulo da obra, amplos demais para darem uma ideia do conteúdo específico de cada um de seus 38 capítulos, indicam o teor deste livro de grandes proporções. Se os substantivos podem sugerir que os editores coordenaram um projeto cujo propósito seria escrever uma história sobre uma região, a referência a povos, no plural, contrabalança essa inclinação. A introdução, escrita pelos organizadores, destaca, em várias passagens, a unicidade da história do Caribe, o "mais antigo palco da expansão além-mar europeia", onde "a modernidade, o capitalismo e a globalização assentaram-se primeiramente", "antecipando e possibilitando os processos de modernização europeus" (:7-12). Mas essa história não é tratada de forma homogênea; ao contrário, todas as contribuições demonstram o quão complexa, irregular, inovadora, fraturada e desigual foi essa história, com suas ressonâncias específicas em cada lugar e para cada sujeito.

Organizada temática e cronologicamente em sete partes, a obra abrange a variada composição étnica e racial da região, lidando com experiências compartilhadas pelos arquipélagos e pelas porções continentais do Caribe - como Belize e as Guianas. Reunindo alguns dos maiores especialistas contemporâneos, o livro é uma acessível introdução a essa complexa área do globo, contendo mapas, um glossário e indicações bibliográficas, elementos que tornam a obra ainda mais atrativa para leitores pouco familiarizados com a realidade caribenha. Todas as contribuições - elaboradas por cientistas políticos, sociólogos, antropólogos, demógrafos, historiadores e geógrafos - são escritas em uma prosa livre de academicismos e visam apresentar um sumário das questões abordadas. A escala, portanto, é propositadamente ampla e as grandes ilhas - Jamaica, Porto Rico, Cuba, São Domingos (República Dominicana e Haiti) - recebem muito mais atenção do que outros territórios. 
A primeira parte do livro tem um caráter basilar, com dois capítulos que tratam da paisagem física e ambiental da região - amplamente transformadas pelas plantações de açúcar e pela indústria do turismo - o capítulo terceiro apresentando um panorama sobre a realidade histórica, social e cultural das populações ameríndias, no período compreendido entre 5000 a.C e 1500 d.C, e o último que investiga a longa história, no Mediterrâneo, de dois elementos centrais para a formação do Caribe colonial: a escravidão e o açúcar.

A segunda parte da obra explora os movimentos pelos quais o sistema de produção da plantation se consolidou primeiramente no Caribe espanhol e, em seguida, nas colônias controladas por outros impérios europeus. As plantations, enormes investimentos sustentados por ampla mão de obra, com uma divisão de trabalho virtualmente industrial e uma sofisticada infraestrutura de transporte e processamento do açúcar, conforme caracterização de Palmié (:136), não eram apenas um tipo de empreendimento agrícola, mas também uma instituição política implantada na organização do espaço colonial. As dramáticas transformações sociais, demográficas, econômicas, políticas e ambientais, decorrentes do plantio do açúcar com o amplo uso de mão de obra escrava, são abordadas nesta parte do livro através da análise do papel de distintos agentes colonizadores, populações autóctones, escravos indígenas e africanos, piratas, quilombolas, bucaneiros - bem como pela reconstituição das complexas e instáveis relações entretidas entre esses grupos.

O século XVII foi um período de mudanças políticas e sociais de longo alcance, marcado pela dizimação das sociedades autóctones (mas não a extinção), pelo surgimento de uma identidade diacrítica entre os criollos das colônias espanholas, pela formação de metrópoles densamente povoadas e multiculturais (como Havana e San Juan) e pela maturação de sociedades que demandavam cada vez mais trabalhadores. Os seis capítulos da terceira parte do livro concentram a análise nesse período histórico, no qual as disputas entre impérios rivais, que nunca foram meras extensões dos conflitos vigentes na Europa, como lembra Games (:201), resultaram no fim da hegemonia espanhola e no consequente estabelecimento definitivo de colônias francesas e britânicas na região. Os holandeses, por sua vez, muito embora não tenham se apossado de vastas extensões territoriais, tiveram um papel notável na infusão de capital nos engenhos de açúcar e no fornecimento de escravos africanos - na região das Guianas, postos comerciais holandeses conectavam uma ampla rede de grupos indígenas, fato pouco destacado na obra.

Os seis capítulos da quarta parte do livro tratam em detalhe das formas de resistência à escravidão e da cultura escrava. A história da vida escrava no Caribe é simultaneamente deprimente e edificante, nas palavras de Morgan (:260). As expressões religiosas, linguísticas, econômicas, identitárias, culturais, culinárias, étnicas, musicais etc. são concebidas como resultado de duas forças que se moldaram mutuamente: a inspiração das distintas culturas africanas e as apropriações seletivas de novas culturas. Após um panorama estimulante sobre as culturas escravas, formas de dominação e de resistência no Caribe (cap. 16), as duas contribuições seguintes tratam de eventos cujos efeitos foram duradouros: as guerras entre potências europeias no século XVIII, com suas repercussões nas colônias caribenhas (cap. 17), e a revolução haitiana (cap. 18), evento de impacto global, cujo entendimento é crucial para entender a história da política moderna, como bem pontua Dubois (:274). 
Os três últimos capítulos centram-se no período da emancipação, com Paton tratando da abolição da escravidão nas colônias não espanholas, Tomich revisitando a clássica obra de Eric Williams para pensar as relações entre capitalismo, escravidão e emancipação no Caribe Britânico e Francês, e Jean Besson analisando como escravos da Jamaica se apropriaram e reinterpretaram preceitos cristãos transmitidos por plantadores e missionários. Faz-se referência, por último, ao destaque dado às inúmeras rebeliões escravas que irromperam na região, bem como à formação de comunidades quilombolas (maroons), notadamente no Suriname e na Jamaica.

Compreender os paradoxos do século XIX, período no qual a progressiva abolição da escravidão andou de mãos dadas com o incremento do uso e da difusão de tecnologias produtivas, sobretudo na monocultura açucareira, é o escopo da quinta parte do livro. Os autores apresentam elementos para compreender a transição entre escravidão e liberdade de forma não linear. No século XIX, testemunhou-se um reforço de hierarquias raciais e diversos descompassos entre as expectativas da classe senhorial e dos escravos quanto ao advento da liberdade, processo muito bem descrito por Heuman e Cooper nos capítulos 23 e 26, respectivamente. Ao mesmo tempo, os princípios basilares de exploração da mão de obra se reconfiguraram com o surgimento de novas tecnologias de controle sobre a vida dos ex-escravos e pela deterioração da mão de obra - uma consequência direta, dentre outros fatores, da importação de trabalhadores contratados de diversas partes do mundo, em especial da China e da Índia. Assim, e como bem sugere o título do capítulo escrito por Aisha Khan, o Caribe não é apenas um amálgama de culturas de origem africana e daquelas de origem europeia: África, Europa e Ásia moldaram as culturas caribenhas. Por fim, esse período de transição marcou a emergência de um novo poder imperial, os Estados Unidos.

As seis contribuições seguintes da sexta parte do livro tratam, de vários ângulos, justamente da emergência e da consolidação das políticas coloniais e neocoloniais estadunidenses na região, cujo efeito mais dramático foi a ascensão de ditadores patrocinados pelos Estados Unidos. Os capítulos não se limitam a reconstituir os processos pelos quais a hegemonia estadunidense se difundiu cada vez mais pelo Caribe. A análise das reações locais, através de revoltas, protestos e revoluções, da produção de intelectuais locais, cujas obras ajudaram a forjar símbolos nacionais e noções de pertencimento, e de movimentos artísticos, culturais, políticos e sociais, ganha destaque. Ainda assim, e como demonstra Ayala, autor do capítulo 29, embora os arranjos políticos provenientes das intervenções estadunidenses não tenham produzido resultados homogêneos, economicamente o resultado dessas intervenções foi a expansão da monocultura açucareira.

Por fim, a sétima e última parte da obra abrange o período entre a última metade do século XX e a contemporaneidade, tratando de temas sensíveis, quais sejam: a Revolução Cubana e as experiências dos(as) cubanos(as) com o socialismo (cap. 34); o processo de independência no Suriname, em Trinidad e Tobago e na Jamaica e o estatuto político ambíguo das "quase colônias modernas" - Porto Rico, Antilhas holandesas, Guadalupe, Martinica e Guiana Francesa (caps. 35 e 36); as espinhosas e complexas relações entre duas nações situadas em uma mesma ilha, Haiti e República Dominicana, as quais foram marcadas por diversas tensões e contradições (cap. 37); os impactos do tráfico de drogas, do turismo e dos paraísos fiscais na região; e os in- 
tensos fluxos imigratórios de caribenhos para outras partes do globo e para outras nações da região (caps. 38 e 39).

The Caribbean: a history of the region and its people certamente apresenta algumas lacunas: questões relativas ao gênero e às relações da região com a América do Sul são pouco exploradas, há pouco espaço para os povos ameríndios, e as regiões das Guianas são relegadas a um segundo plano (a não ser quando a realidade estudada corresponde às chaves de leitura clássicas sobre o Caribe). Se as narrativas mestras sobre a região são salientadas em diversas partes do livro, seja pelos apelos à unicidade da história da região, seja pelo recurso ao consagrado conceito de "crioulização", as referências a outras histórias e experiências oferecem um contraponto interessante. O alcance amplo da obra, tanto em termos de público-alvo como de sua impressionante diversidade de temas, a tornam uma referência indispensável para os leitores interessados em se familiarizar com a complexa história da região. Por conta disso, do ponto de vista da antropologia, poder-se-ia perguntar: em que medida a escala ampla e de longa duração fortalece, ou enfraquece, o registro e a descrição de histórias específicas e localizadas?

PICARD, David. 2012. Tourism, magic and modernity: cultivating the human garden. New York/ Oxford: Berghahn Books. 189 pp.

\section{Diana Espirito Santo}

Centro em Rede de Investigação em Antropologia (CRIA); Faculdade de Ciências Sociais e Humanas, Universidade Nova de Lisboa

As ilhas tropicais são sedutoras para o público ocidental; não é surpreendente que embutidas na percepção da sua "magia" estejam algumas fortes suposições sobre a modernidade e seus opostos socialmente construídos - primordiais passados virgens, natureza, tradição, autenticidadesuposições estas que se apoiam em concepções culturalmente específicas do tempo e da história, entre outras coisas. Tourism, magic and modernity, de David Picard, é um livro importante porque visa abordar as estruturas históricas, ideológicas e discursivas através das quais diversos povos de discrepantes posições sociais e locais procuram cultivar a sua imagem, o "jardim" que é a sua aldeia ou nação, os ideais dos seus antepassados, todos em face de formas aceleradas de mudança e de contacto. Na verdade, este livro é menos sobre o que seu título sugere - o turismo na ilha Índica da Reunião (La Réunion) - e mais sobre "encontros" de várias espécies, e sua indispensabilidade ontológica na constituição e na negociação de um sentido contínuo de "self", pessoal e prolongado.

Enquadrando a dialética de "selfing" e "othering" que ocorre por meio de contacto de forma mais ampla em termos de "magia", Picard esvazia o conceito da sua meta-armação cognitivamente pejorativa na história da antropologia, deslocando o seu foco para a naturalidade de uma necessidade imanentemente humana para se autofazer através de relações de todos os tipos. A "magia" à qual alude o autor analiticamente refere-se, portanto, menos à essência de algo ou de alguém do que aos processos pelos quais as "coisas" (pessoas, lugares, tradições) se tornam imbuídas de uma aura ou aparência mágica, constituída por e refractada através de vários âmbitos de actividade e de retórica. Picard ressuscita a magia, como ele diz, seguindo Sahlins, a serviço de uma compreensão dos caminhos "através dos quais as sociedades mobilizam os atributos e as qualidades de divindades ou inimigos, ancestrais ou afins, como 
condição necessária da sua própria existência" (:6). Neste sentido, enquanto baseado numa etnografia fortemente focada no seu envolvimento com a indústria do turismo e na construção de ideias de modernidade neste particular "paraíso", o livro de Picard fala transversalmente com outros conjuntos de literatura, desde a sociologia e a história de jardins e sua relação com a democracia, exploradas no oitavo capítulo, até o não mencionado aqui, mas também fundamental corpo de trabalho sobre a pessoalidade e sua predicação em formas de contacto e de fronteira.

La Réunion teve o seu quinhão de convulsão económica, política e social ao longo dos últimos 50 anos. Esta pequena ilha-nação no Oceano Índico, constituída demograficamente por pessoas de ascendência africana, madagascarense, indiana, europeia e chinesa, foi declarada départment d'outre-mer em 1946, com resultados mistos. Na década de 1960, o recém-eleito primeiro-ministro francês, Michel Debré, um acérrimo defensor dos interesses coloniais da Mère Patrie, introduziu o estado social francês na ilha, sistematizando uma estrutura póscolonial de dependência económica que, embora tenha dado à população acesso ao consumo antes desconhecido e a novas formas de desenvolvimento social, de acordo com Picard, "deixou os homens num papel social e simbolicamente ambivalente, como chefes sem poder das famílias" (:34), entre outras coisas. Ao mesmo tempo, reforçou uma imagem do povo da ilha como as "crianças" de França, incapazes, por definição, de retribuírem e se autonomizarem.

No contexto desta economia artificial e do rápido crescimento populacional, por um período de duas décadas, a partir dos anos 1960, um grande número de ilhéus emigrou para a França em busca de emprego, alguns deles tendo retornado na década de 1990, formando elites cujos ideais e novas formas de sociabilidade produziriam um impacto considerável. Na ausência de uma economia viável e sustentável, La Reunión foi elaborando as suas estratégias de turismo, embora contenciosamente. Poderosos grupos de interesse, resistentes à comodificação da ilha e seus ambientes naturais e culturais, surgiram nas décadas de 70 e 80 e no decorrer dos anos 90 do século passado. Esses movimentos e as agências governamentais concordariam que o desenvolvimento turístico iria ocorrer em pequena escala, orientado para a descoberta da ilha através do seu património cultural, natural e económico (:37). La Réunion tornar-se-ia um "jardim humano".

Ao mesmo tempo, como Picard mostra no capítulo 6 sobre as políticas ambientais por detrás da protecção dos recifes de corais, esses processos foram muito menos democráticos do que pareciam ser. Os passos que levaram à abrangência formal das "mágicas" barreiras de coral num sistema marinho protegido, por exemplo, reforçaram as divisões sociais, em vez de dissolvê-las, pois as partes interessadas excluíram de suas formulações as populações mais afectadas pelas políticas de protecção: as famílias de pescadores tradicionais, pobres, e em grande parte analfabetas.

Por um lado, o livro é uma exploração de como ideais ocidentais sobre ilhas tropicais, muitas vezes românticos, têm um impacto na vida social e nos destinos dos habitantes desses lugares, que são chamados a responder a estas e muitas vezes fazem-no através da apropriação, do mimetismo e, ocasionalmente, expulsando essas mesmas ordens hegemónicas (e pessoas). A noção difundida entre turistas ocidentais de que a viagem para locais bonitos e o contacto com bonitos "outros" "transforma" o experimentador é um aspecto dessa ontologia do "outro" 
mágico que Picard articula no primeiro capítulo, em que se debruça sobre os encontros turísticos entre grupos de viajantes alemães. É esse mesmo olhar, diz ele, que tem "retropicalizado" ilhas em todo o mundo segundo os "paradigmas modernistas da natureza, da beleza e do tempo" (:5). Mas, como Picard mostra em capítulos posteriores, essas objectificações têm ramificações muito mais profundas quando articuladas em níveis transnacionais, e de políticas culturais.

No terceiro capítulo, sobre a génese de um novo eco-museu no vale historicamente romantizado de Salazie, Picard apresenta-nos, claramente, a maneira pela qual seus habitantes se emaranham não apenas com lógicas dominantes e eurocêntricas de autenticidade e herança, mas nas suas próprias transfigurações das lógicas. O capítulo 7, sobre a organização de festivais locais que têm como objectivo celebrar a história e a identidade crioula, é uma prova da plurivocalidade destas transfigurações.

Assim, por outro lado, este é um livro sobre o cultivo de espaços - por meio do desenvolvimento do turismo e da promulgação cultural - por actores locais, que configuram a sua própria modernidade e lugar no "ethnoscape" global, tomando as regras do jogo e refazendo-as nos seus próprios termos. Em alguns casos, numa escala prática, isso levou a um choque de entendimentos entre as narrativas da metrópole francesa da localidade, vista como integrada numa matriz maior de património nacional, e as metanarrativas dos actores reunenses sobre a "crioulidade", os quais se recusam à assimilação aos "de fora", enquanto comemoram as diferenças internas geradas através da interface histórica com eles. O desenvolvimento turístico ocorre, particularmente desde a década de 1990, neste palco de interesses concorrentes para uma determinada imagem da nação, aquela que a lança, de forma paradoxal, tanto como global como essencialmente "mágica".

O segundo capítulo do livro, dedicado à história de Orom, um guia de turismo treinado através da primeira iniciativa turística do país, demonstra soberbamente este jogo duplo de imaginários, bem como as suas tensões e contradições. Orom descreve a ilha como um "lugar cheio de sucos, cores, sabores, cheiros deliciosos, legumes monstruosamente ampliados e plantas, flores que se parecem com os órgãos sexuais" (:43), "um reino mágico capaz [...] de restabelecer o reinado de uma natureza idealizada essencial de todas as coisas" (:45). Ao mesmo tempo em que se constitui como um dos produtos mágicos da ilha, mediando a tradição e a modernidade, Orom reflexivamente representa ou actua a "sua ligação com as tradições 'crioulas' como valores fundamentais da sua actividade turística" (:46), revelando uma ambiguidade, ou mesmo senso de tragédia. Picard desenvolve uma análise dessas performances ao entender a sua relação com a lógica cultural difusa da hospitalidade em La Reunión de forma mais ampla, especialmente com o que ele chama de "sistema de comunicação" (:75) de kartié, um complexo social de práticas e expectativas no qual "dar uma boa imagem" é fulcral.

A narrativa do livro lê-se sem esforço. Isto é devido, em parte, ao que Picard afirma ser o seu estilo jornalístico de escrita, característico da reportagem longa, que admissivelmente funciona bem aqui; mas mais importante, do ponto de vista desta leitora, porque Picard permite que os actores do livro e suas histórias simplesmente falem por si, sem recurso a excesso de teorizações cansativas. Enquanto alguns argumentos são repetitivos - a noção de que La Réunion é um palco intercultural onde a história e a identidade são realizadas, através e, talvez, apesar de seus paradoxos inumeráveis, por exemplo, 
está reiterada nos argumentos centrais de cada um dos capítulos do livro - Picard faz apenas o suficiente trabalho conceitual e teórico para manter o leitor ligado às maiores implicações de seus dados, desvendando os seus fios de forma clara e sem pretensiosismos.

Este aspecto é certamente ajudado pela destreza que Nelson Graburn, no seu prefácio ao livro (:x), vê como produto do ecletismo intelectual de Picard, a sua fluidez com a literatura bem além da antropologia. Nem o seu próprio investimento na ilha, claramente profundo tanto em termos de tempo como emoção, é expresso de forma indulgente. Ao contrário, Picard escreve apenas o suficiente de si mesmo no texto para elucidar os caminhos do jardim que nós, ao seguilo, devemos também trilhar. Economia e concisão são certamente dois dos pontos fortes deste livro. Mas isto não nos afasta das cativantes e detalhadas vinhetas etnográficas que Picard tece para seu leitor com humor e cuidado. 